\title{
Application of Response Surface Method as an Experimental Design to Optimize Clarification Process Parameters for Sugarcane Juice
}

\section{Umesh Kumar PK* and Khan Chand}

Department of Post Harvest Process and Food Engineering, College of Technology, G. B. Pant University of Agriculture and Technology, Pantnagar, Uttrakhand, India

\begin{abstract}
In this study, the response surface method and experimental design were applied for optimization of independent variables for clarification of sugarcane juice. A central composite design, with 6 axial points, 8 factorial points and 6 replicates at the centre point were used to build a model for predicting and optimizing clarification process parameters. The independent parameters viz Temperature $\left(73.59,77,82,87\right.$ and $\left.90.41^{\circ} \mathrm{C}\right)$, Activated charcoal thickness $(0.83,1.0$, and $1.25,1.5$ and $1.67 \mathrm{~mm})$ and deola $(0.063,0.2,0.4,0.6$ and $0.74 \mathrm{~g} / \mathrm{l})$ were selected and analyzed. Statistical checks (ANOVA table, R2 value, model lack of fit test and F-value) indicating that the model was adequate for representing the experimental data. The dependent parameters measured were viscosity, ${ }^{\circ}$ Brix, and total solids values. Optimum values of process parameters obtained by using simultaneous optimization of dependent parameters were: $77.55^{\circ} \mathrm{C}$ temperature, $1.5 \mathrm{~mm}$ activated charcoal thickness and $0.48 \mathrm{~g} / \mathrm{lit}$ deola.
\end{abstract}

Keywords: Sugarcane juice; Temperature; Deola and thickness; RSM optimization

\section{Introduction}

Sugarcane (Saccharum officinarum) is one of the most important agro-industrial crops in our country. In 2009-10, the total production of sugarcane in the country was around 292 million tonnes, producing about $63.50 \%$ of white sugar and $26.60 \%$ gur and khandsari [1] whereas in 2010-11 the total production of sugarcane was around 340 million tonnes, producing nearly 70.70 million tonnes white sugar and 17.40 million tonnes gur and khandsari. India stands second among other sugarcane growing countries, contributing nearly $20.40 \%$ area and $18.60 \%$ production. About $50-60 \%$ of the cane produced is utilized for production of jaggery (gur) and open pan sugar- khandsari [2].

Jaggery is one of the ancient sweetening agent and is an integral part of the rural diet in many countries. It is one of the most important sweeteners in India. Jaggery (also known as gur) is a traditional unrefined non-centrifugal sugar consumed in Asia, Africa, Latin America and the Caribbean [3]. Although labelled as the poor man's sugar, most Indians consume gur in some form or the other. It is a concentrated product of cane juice without separation of the molasses and crystals and can vary from golden brown to dark brown in color. It contains upto $50 \%$ sucrose, upto $20 \%$ invert sugars with some other insoluble matter such as ash, proteins and bagasse fibres [4]. It is directly consumed by human and in animal feed mixtures. Both white sugar production and jaggery manufacturing involve extraction of juice from sugarcane. The quality of juice depends upon the quality of sugarcane which in turn depends on several factors like climatic conditions, soil characteristics, varieties, individual cane, tillers and their age, etc [5] and the method of extraction [6]. The non-sugar impurities present in the juice, both suspended and dissolved have to be removed by clarification for obtaining both better quality sugar and jaggery. Thus, juice clarification process aims at removal of maximum of non-sugars and colouring matters. Inadequacies of process efficiency at this stage are reflected in impurities in the products and lower exhaustion and higher production of molasses. The main byproducts of the sugarcane industry are bagasse and molasses; bagasse is mainly used as fuel. It is also used for production of compressed fiber board, paper, plastics and furfural. Molasses is used in distilleries for the manufacture of ethyl alcohol, butyl alcohol, citric acid etc. The importance of jaggery is well known due to its great nutritive and medicinal value.
The main objectives of juice clarification are to raise its $\mathrm{pH}$ and eliminate suspended solids. Colour removal is at best considered a secondary objective, rarely monitored by the mill laboratory and to our knowledge never used as a criterion to assess, let alone control, the process. The use of $\mathrm{SO}_{2}$ is widespread in clarifying juice in production of plantation white sugar, however periodic spikes in sulfur prices and sugar quality issues have stimulated efforts to reduce or even eliminate its use. With that in mind, a carbonation process has been tested and compared with standard sulfitation and defecation. Besides eliminating the use of sulfur, carbonation would also provide a means to utilize and sequester some of the excess $\mathrm{CO}_{2}$ that may be available cost-free in some sugar factories from molasses or juice fermentation. The traditional double-carbonation process was used initially in cane juice clarification. The process of clarification also aims at preventing the formation of non-sugars during heating due to the acidity of the juices [7]. In clarification of sugarcane juice for jaggery manufacturing, the old crude methods still exist with slight modifications in clarificants. Effective clarification makes the juice clear and light in colour and the jaggery produced is more crystalline, harder, less hygroscopic and more hygienic. Clarificants used are mostly of vegetative origin, but some chemicals have also been used in combination with vegetative clarificants. All these chemicals, except lime, brighten the colour of the jaggery initially, but the colour of the jaggery becomes dull during storage. The chemical clarificants are not preferred due to their adverse effects. Therefore, use of alternative clarificants is explored.

Unfortunately, very few studies have been reported on clarification of sugarcane juice by activated charcoal although there is an immense

\section{${ }^{*}$ Corresonding author: Umesh Kumar PK More, Department of Post Harvest Process and Food Engineering, College of Technology, G. B. Pant University of Agriculture and Technology, Pantnagar, U. S. Nagar, Uttrakhand, India, Tel: 07500734737; E-mail: kcphpfe@gmail.com}

Received January 20, 2015; Accepted January 30, 2015; Published February 06, 2015

Citation: Umesh Kumar PK, Chand K (2015) Application of Response Surface Method as an Experimental Design to Optimize Clarification Process Parameters for Sugarcane Juice. J Food Process Technol 6: 422. doi:10.4172/21577110.1000422

Copyright: (c) 2015 Umesh Kumar PK, et al. This is an open-access article distributed under the terms of the Creative Commons Attribution License, which permits unrestricted use, distribution, and reproduction in any medium, provided the original author and source are credited. 
possibility. Hence, the present study will be undertaken with the following objectives:

I. To study the effect of clarification of sugarcane juice by activated charcoal.

AI. Optimization of processing parameter for clarification of sugarcane juice.

\section{Materials and Methods}

\section{Raw material}

In this study, sugarcane juice, deola and activated charcoal were used as a raw materials out of which sugarcane juice and deola were collected from crop research center (CRC) Pantnagar and activated charcoal was procured from M/s R. K. Scientific Rudrapur, Udham Singh Nagar. The juice was filtered with help of four layers muslin cloth (maximum pore size $2 \mathrm{~mm}$ ) to remove big impurities.

\section{Experimental procedure}

The preliminary experiments were carried out to find out the physicochemical properties such as $\mathrm{pH}$, reducing sugar, total phenol, sucrose content and colour of sugarcane juice. In this process firstly we crushed the sugarcane juice after that we did the pre-filtration process from the four layer of muslin cloth and during the pre-filtration process remove the all suspended particle and big impurities. The juice was heated at different temperature and different quantity of deola then juice was passed away different charcoal thickness in the Buchner funnel. The thickness of charcoal was made between cotton bed like a sandwitch. After settled the thickness the juice was filtered by Buchner funnel at constant vacuum pressure and the juice was collected in the filtration flask. After that the physicochemical properties of clarified juice was measured by standard method (Figure 1).

\section{Design of experiments}

When the process factors (independent parameters) satisfy an

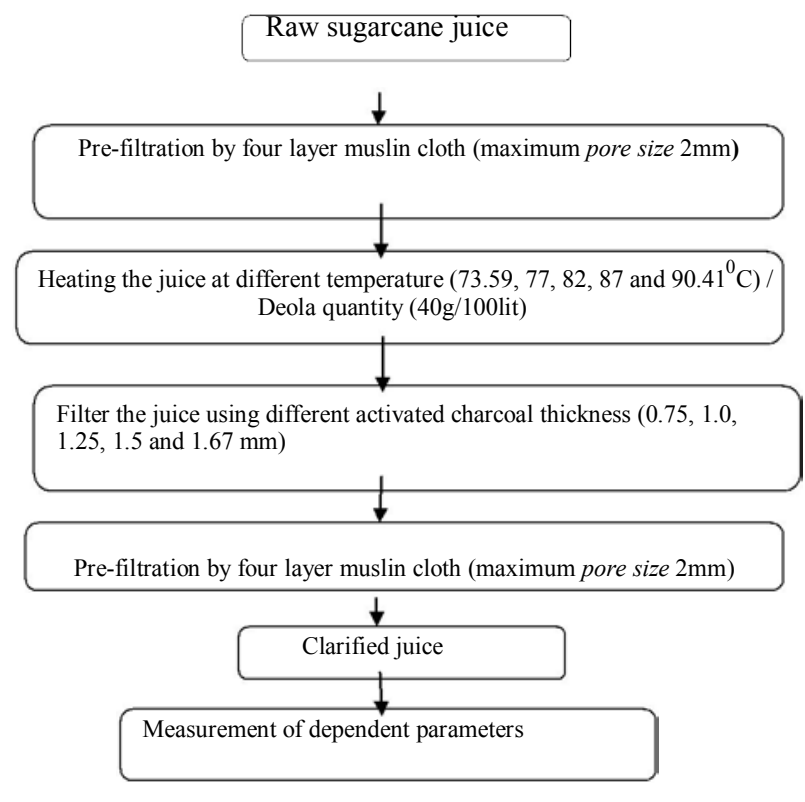

Figure 1: Process flow chart for Clarification of Sugarcane juice. important assumption that they are measurable, continuous, and controllable by experiments, with negligible errors, the RSM procedure was carried out as follows:

1) A series of experiments were performed for adequate and reliable measurement of the response of interest.

2) A mathematical model of the second-order response surface with the best fit was developed.

3) The optimal set of experimental parameters producing the optimum response value was determined.

A central composite design (CCD), which is very efficient design tool for fitting second order models (Montgomery, 2001) was selected for use in this study. The number of tests required for a CCD include: the standard $2^{\mathrm{k}}$ factorial points, $2 \mathrm{k}$ axial points fixed axially at a distance, say $\alpha$, from the centre to generate quadratic terms, and the replicate tests at the centre of experimental region; where $\mathrm{k}$ is the number of variables. Replicates of the test at the centre are very important as they provide an independent estimate of the experimental error. Generally, three to six centre runs are recommended [8]. A CCD for 3 factors (temperature, activated charcoal thickness and deola), with 6 replicates at the centre resulting in total $2^{3}+2^{\star} 3+6=20$ runs. A composite central design is made rotatable by the choice of $\alpha$. A value of $\alpha=2^{k / 4}$ assures rotation of the CCD [9]. In this study $\mathrm{k}$ was 3 factors (temperature, activated charcoal thickness and deola), therefore $\alpha$ became 1.68 .

In order to define the experimental domain explored, preliminary experiments were carried out to determine narrower, more effective range of temperature, activated charcoal thickness and deola to designing the experimental runs. It was found from the preliminary tests that the dependent variables were more effective in the range of temperature from 73.59 to $90.41^{\circ} \mathrm{C}$, activated charcoal thickness in the range from 0.83 to $1.67 \mathrm{~mm}$ and deola in the range from 0.063 to 0.74 $\mathrm{g} /$ lit. Once the desired value ranges of the variables had been defined, they were coded to lie at \pm 1 for the factorial points, 0 for the centre points, and $\pm \alpha$ for axial points. The codes were calculated as functions of the range of interest of each factor, as shown in Table 1. A central composite design with 8 factorial points, 6 axial points and 6 additional experimental trials (run number 15-20) as replicates of the centre point are given in Table 2 .

In order to determine if a relationship existed between the factors and the responses investigated, the collected data was analyzed statistically using regression analysis. A regression design is employed to model a response as a mathematical function (either known or empirical) of a few continuous factors and 'good' model parameter estimates are desired. Each response of $\mathrm{Y}$ can be represented by a mathematical equation that correlates the response surface. The response can be expressed as second-order polynomial equations, according to Eq. (1):

$$
\mathrm{Y}=\beta_{0}+\sum_{\mathrm{i}=1}^{\mathrm{k}} \beta_{\mathrm{i}} \mathrm{X}_{\mathrm{i}}+\sum_{\mathrm{i}=1}^{\mathrm{k}} \sum_{\mathrm{j}=\mathrm{i}+1}^{\mathrm{k}} \beta_{\mathrm{ij}} \mathrm{X}_{\mathrm{i}} \mathrm{X}_{\mathrm{j}}+\sum_{\mathrm{i}=1}^{\mathrm{k}} \beta_{\mathrm{ii}} \mathrm{X}_{\mathrm{i}}^{2}
$$

Where Y predicted response used as a dependent variable; $\mathrm{k}$ the number of independent variables (factors), $X_{i}(I=1,2,3)$ the input predictors of controlling variables (factors); $\beta_{0}$ the constant coefficient, and $\beta_{\mathrm{i}}, \beta_{\mathrm{ij}}$ and $\beta_{\mathrm{ii}}$ the coefficients of linear, interaction and quadratic term, respectively. The coefficient parameters were estimated using a multiple linear regression analysis employing the software DesignExpert 8.0.6. 
Citation: Umesh Kumar PK, Chand K (2015) Application of Response Surface Method as an Experimental Design to Optimize Clarification Process Parameters for Sugarcane Juice. J Food Process Technol 6: 422. doi:10.4172/2157-7110.1000422

\begin{tabular}{|l|c|c|c|c|c|c|c|}
\hline Independent variables & \multicolumn{7}{|c|}{ Coded levels } \\
\hline Name & Code & -1.68 & -1 & 0 & 1 & 1.68 \\
\hline & \multicolumn{7}{|c|}{ Actual Levels } \\
\hline Temperature $\left({ }^{\circ} \mathrm{C}\right)$ & $\mathrm{X}_{1}$ & 73.59 & 77 & 82 & 87 & 90.41 \\
\hline Charcoal Thickness $(\mathrm{mm})$ & $\mathrm{X}_{2}$ & 0.83 & 1 & 1.25 & 1.5 & 1.67 \\
\hline Deola $(\mathrm{g} /$ /it) & $\mathrm{X}_{3}$ & 0.063 & 0.2 & 0.4 & 0.6 & 0.74 \\
\hline
\end{tabular}

Table 1: Values of independent variables in coded and actual form.

\begin{tabular}{|c|c|}
\hline Code & Actual value of factor \\
\hline$-\alpha$ & $X$ min \\
\hline-1 & $(\alpha-1) x_{\text {max }}+(\alpha+1) x_{\min } / 2 \alpha$ \\
\hline 0 & $x_{\text {max }}+x_{\text {min }} / 2$ \\
\hline+1 & $(\alpha-1) x_{\text {min }}+(\alpha+1) x_{\max } / 2 \alpha$ \\
\hline$+\alpha$ & $X \max$ \\
\hline \multicolumn{2}{|c|}{ Xmax and Xmin : maximum and minimum value of $X$} \\
\hline
\end{tabular}

Table 2: Relationship between the coded and actual values of a factor.

\section{Viscosity}

To determine the kinematic viscosity and absolute viscosity of the given lubricating oil at different temperatures using Redwood Viscometer by Guthrie:

Kinematic Viscosity $=\gamma=A t \mathrm{~B} / \mathrm{t}$

Where $A=0.26, B=172, t=$ Saybolt second, unit of viscosity stokes or $\mathrm{t}$ in centi stokes

\section{Measurement of ${ }^{\circ}$ Brix}

When a ray of light passes obliquely from one optical medium into another, it is bent or refracted because the velocity of light varies inversely with the optical density of the medium through which the light is passing. It will bend toward perpendicularly to the surface when passing into a medium of greater optical density and away from it when passing into a medium of lesser optical density. The refractive index indicates the degree of bending or the ratio of the velocities of light in passing from one medium to another. Measurements of the refractive index are translated to percentage composition of the sample in a refractometer. The reading in the scale corresponds to the total soluble solids (TSS) actually present in the sample. For measurement of TSS present in the sugarcane juice, one or two drops of the juice were put on the prism of a hand refractometer and the reading was taken after closing the lid. For correct measurement of ${ }^{\circ}$ brix, temperature correction was done.

Total solids: Total solid content of the juice before and after the clarification, was determined by drying a known sample ( $5 \mathrm{~g})$ of each in a Petri dish for 40 hours at $80-95^{\circ} \mathrm{C}$. The difference between the two gives the extent of clarification. Total solids per $100 \mathrm{~g}$ of the sample was computed using the equation

$S^{\prime}=\left(W_{1}-W_{2}\right) \times 20$

where,

$\mathrm{S}^{\prime}=$ total solids per $100 \mathrm{~g}$ of juice

$\mathrm{W}_{1}=$ weight of Petri dish containing dried sample, $\mathrm{g}$

$\mathrm{W}_{2}=$ weight of Petri dish, $\mathrm{g}$

Through preliminary experiments, it was found that the total solid content of crude pectinase.

\section{Results and Discussion}

Twenty observed responses were used to compute the models using the least square methods. The five responses (viscosity, ${ }^{\circ} \mathrm{Brix}$ and, total solid,) were correlated with the three independent variables (temperature, activated charcoal thickness and deola) (Table 3), using second-order polynomial, as represented by Eq 1. From the experimental data, quadratic regression models for different responses were obtained, as shown in Eqs. 2-6.

\section{Model fitting}

Viscosity: Second order predicted quadratic equation for viscosity

$\mathrm{Y}=2.064+0.019 \mathrm{X}_{1}+0.0517 \mathrm{X}_{2}-0.062 \mathrm{X}_{3}+0.091 \mathrm{X}_{1} \mathrm{X}_{2}+0.131 \mathrm{X}_{1} \mathrm{X}_{3}$ $0.053 \mathrm{X}_{2} \mathrm{X}_{3}-0.024 \mathrm{X}_{1}^{2}+0.028 \mathrm{X}_{2}^{2}-0.113 \mathrm{X}_{3}^{2}$

Where

$\mathrm{Y}$ is viscosity (centistokes)

$\mathrm{X}_{1}, \mathrm{X}_{2}$ and $\mathrm{X}_{3}$ are coded variables for temperature, charcoal thickness and deola respectively. From the eq. 2 viscosity will increase by decreasing the linear term of deola $\left(\mathrm{X}_{3}\right)$ and the quadratic terms of deola $\left(\mathrm{X}_{3}{ }^{2}\right)$, while it will decrease by increasing the linear terms of activated charcoal thickness $\left(\mathrm{X}_{2}\right)$, interactive terms of temperature and deola $\left(\mathrm{X}_{1} \mathrm{X}_{3}\right)$ (Table 4).

Effect of viscosity at linear, quadratic and interactive levels is reported. It shows that the effect at quadratic and interactive level were highly significant $(\mathrm{P}<0.01)$ while the effect of linear levels was $(\mathrm{P}<0.05)$ significant.

Second order mathematical model (Eqn-1) was fitted in to the viscosity data to analyze the effect of variables. The model was significant $(\mathrm{P}<0.05)$ with $\mathrm{F}$ value of 6.0. The coefficient of determination $\left(\mathrm{R}^{2}\right)$ of the regression model for viscosity was $84.38 \%$, which implies that the model accounted $84.38 \%$ variability in the data. Lack of fit was insignificant so model was considered adequate as it had a high $\mathrm{R}^{2}$ value and significant $\mathrm{F}$ value. Considering all the above criteria, the following model was selected for representing the variation of viscosity for further analysis. Lack of fit was insignificant so model was considered adequate because $\mathrm{F}_{\mathrm{cal}}>\mathrm{F}_{\mathrm{tab}}$.

${ }^{\circ}$ Brix: Second order predicted quadratic equation for brix was given below

$\mathrm{Y}=16.162-0.0000 \mathrm{X}_{1}+0.26959 \mathrm{X}_{2}-0.14645 \mathrm{X}_{3}-0.25000 \mathrm{X}_{1} \mathrm{X}_{2}+$ $0.2500 \mathrm{X}_{1} \mathrm{X}_{3}+0.000 \mathrm{X}_{2} \mathrm{X}_{3}-0.03228 \mathrm{X}_{1}^{2}+0.4980 \mathrm{X}_{2}^{2}+0.3216 \mathrm{X}_{3}^{2} \ldots \ldots \ldots \ldots \ldots . . .3$

\begin{tabular}{|l|c|c|c|}
\hline Independent variables & & Coded levels & Actual levels \\
\hline Temperature & $\left(\mathrm{X}_{1}\right)$ & -0.89 & 77.55 \\
\hline Charcoal thickness & $\left(\mathrm{X}_{2}\right)$ & 1 & 1.5 \\
\hline Deola & $\left(\mathrm{X}_{3}\right)$ & 0.12 & 0.48 \\
\hline
\end{tabular}

Table 3: Optimum levels of independent variables.

\begin{tabular}{|l|c|c|c|c|c|}
\hline Source & DF & SS & MS & FCal & Ftab \\
\hline Model & 9 & 0.53 & 0.059 & $6^{\star \star *}$ & 4.94 \\
\hline Linear & 3 & 0.09596 & 0.0319 & $3.26^{\star *}$ & 3.02 \\
\hline Quadratic & 3 & 0.20479 & 0.0682 & $6.95^{\star * *}$ & 4.94 \\
\hline Interactive & 3 & 0.22753 & 0.0758 & $7.73^{\star \star *}$ & 4.94 \\
\hline Error & 10 & 0.0989 & 0.0098 & & \\
\hline Total & 19 & $\mathbf{0 . 6 2 7 1 8}$ & & \\
\hline ***$,{ }^{* *},{ }^{*}$ Significant at 1, 5 and 10\% level of significance respectively \\
\hline
\end{tabular}

Table 4: ANOVA for Viscosity. 
Citation: Umesh Kumar PK, Chand K (2015) Application of Response Surface Method as an Experimental Design to Optimize Clarification Process Parameters for Sugarcane Juice. J Food Process Technol 6: 422. doi:10.4172/2157-7110.1000422

Page 4 of 6

Where,

$\mathrm{Y}$ is ${ }^{0}$ Brix

Brix of Sugarcane juice was before clarification $19^{\circ}$ brix after clarification from 18 to $16^{\circ}$ brix. The results of regression analysis of ${ }^{\circ}$ brix. Second order mathematical model $\left(\mathrm{Eq}^{\mathrm{n}}-1\right)$ was fitted in to the brix data to analyze the effect of variables. The model was significant $(\mathrm{P}<0.01)$ with $\mathrm{F}_{\text {tab }}$ value of 7.18. The coefficient of determination $\left(\mathrm{R}^{2}\right)$ of the regression model for reducing sugar was $86.60 \%$, which implies that the model accounted $86.60 \%$ variability in the data. Lack of fit was insignificant so model was considered adequate as it had a high $\mathrm{R}^{2}$ value and significant $\mathrm{F}$ value.

Effect of ${ }^{\circ}$ brix at linear, quadratic and interactive levels is reported in AOVA (Table 5). It shows that the effect of linear level was significant $(\mathrm{P}<0.1)$. While the effect of quadratic and interactive level were found no significance.

Total solid: The second order predicted quadratic equation for total solid

$\mathrm{Y}=6.873-0.220 \mathrm{X}_{1}+0.514 \mathrm{X}_{2}-0.169 \mathrm{X}_{3}-0.221 \mathrm{X}_{1} \mathrm{X}_{2}+0.241 \mathrm{X}_{1} \mathrm{X}_{3}-$

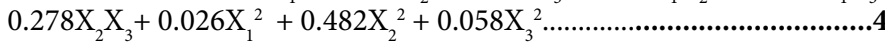

Total solid of Sugarcane juice was varied before clarification 19.1 to $26.5 \mathrm{~g}$ and after clarification from 9.54 to $6.74 \mathrm{~g}$. Table 6 reports the results of regression analysis of total solid. Second order mathematical model (Eqn-3.2) was fitted in to the total solid data to analyze the effect of variables. The model was significant $(\mathrm{P}<0.05)$ with $\mathrm{F}$ value of 4.98 . The coefficient of determination $\left(\mathrm{R}^{2}\right)$ of the regression model for total solid was $81.76 \%$, which implies that the model accounted $81.76 \%$ variability in the data. Lack of fit was insignificant so model was considered adequate as it had a high $\mathrm{R}^{2}$ value and significant $\mathrm{F}$ value.

$\mathrm{X}_{1}, \mathrm{X}_{2}$ and $\mathrm{X}_{3}$ are coded variables for temperature, charcoal thickness and deola respectively. Increase the positive terms the response will increase and decrease the negative terms the response will decrease.

Density: Second order predicted quadratic equation for density was given below

$\mathrm{Y}=0.7661-0.0017 \mathrm{X} 1+\quad 0.0030 \mathrm{X} 2-0.0013 \mathrm{X} 3-0.0002 \mathrm{X} 1 \mathrm{X} 2+$ $0.0026 \mathrm{X} 1 \mathrm{X} 3-0.0026 \mathrm{X} 2 \mathrm{X} 3-0.0002 \mathrm{X}_{1}{ }^{2}+0.0022 \mathrm{X}_{2}{ }^{2}-0.0016 \mathrm{X}_{3}{ }^{2} \ldots \ldots \ldots . .5$

\begin{tabular}{|c|c|c|c|c|c|c|}
\hline & Source & DDF & SS & MS & $\mathbf{F F}_{\mathrm{Cal}}$ & Ftab \\
\hline 1 & Model & 9 & 7.1 & 0.79 & $7.18^{\star \star \star}$ & 4.94 \\
\hline 2 & Linear & 3 & 1.28 & 0.42 & $3.81^{* \star}$ & 3.02 \\
\hline 3 & Quadratic & 3 & 5.07 & 1.69 & 15.36 & \\
\hline 4 & Interactive & 3 & 1 & 0.33 & $3.0^{*}$ & 2.34 \\
\hline \multirow[t]{2}{*}{5} & Error & 10 & 1.1 & 0.11 & & \\
\hline & Total & 19 & 8.45 & & & \\
\hline
\end{tabular}

Table 5: ANOVA for ${ }^{0}$ brix.

\begin{tabular}{|l|c|c|c|c|c|}
\hline Source & DF & SS & MS & FCal & Ftab \\
\hline Model & 9 & 9.51 & 1.04 & $4.98^{* *}$ & 4.94 \\
\hline Linear & 3 & 4.73 & 1.57 & $7.5^{\star * *}$ & 4.94 \\
\hline Quadratic & 3 & 3.40 & 1.13 & $5.39^{* *}$ & 3.02 \\
\hline Interactive & 3 & 1.48 & 0.49 & 2.34 & \\
\hline Error & 10 & 2.12 & 0.21 & & \\
\hline Total & $\mathbf{1 9}$ & $\mathbf{1 1 . 7 3}$ & & \\
\hline ***, ** ${ }^{*}$ Significant at 1,5 and 10\% level of significance respectively
\end{tabular}

Table 6: ANOVA for total solid.
Where,

$\mathrm{Y}$ is density $(\mathrm{g} / \mathrm{cc})$

$\mathrm{X}_{1}, \mathrm{X}_{2}$ and $\mathrm{X}_{3}$ are coded variables for temperature, charcoal thickness and deola respectively.

From the above equation density will increase by decreasing the linear terms of temperature $\left(\mathrm{X}_{1}\right)$, linear terms of deola $\left(\mathrm{X}_{3}\right)$, interactive terms of activated charcoal and deola $\left(\mathrm{X}_{2} \mathrm{X}_{3}\right)$, interactive terms of temperature and activated charcoal thickness and quadratic terms of deola. while it will be decreased by increasing the linear terms of activated charcoal $\left(\mathrm{X}_{2}\right)$, interactive terms of temperature and deola $\left(\mathrm{X}_{1} \mathrm{X}_{3}\right.$ ) and quadratic terms of activated charcoal thickness $\mathrm{X}_{2}^{2}$.

Density of Sugarcane juice was varied before clarification 0.8074 to $0.8076 \mathrm{~g} / \mathrm{cc}$ after clarification from 0.7787 to $0.7565 \mathrm{~g} / \mathrm{cc}$. The results of regression analysis of density. Second order mathematical model (Eqn 1) was fitted in to the density data to analyze the effect of variables (Table 7). The model was significant $(\mathrm{P}<0.05)$ with $\mathrm{F}_{\text {tab }}$ value of 10.60 . The coefficient of determination $\left(\mathrm{R}^{2}\right)$ of the regression model for reducing sugar was $90.51 \%$, which implies that the model accounted $90.51 \%$ variability in the data. Lack of fit was insignificant so model was considered adequate as it had a high $\mathrm{R}^{2}$ value and significant $\mathrm{F}$ value.

Graphical interpretation of ${ }^{\circ} \mathrm{Brix}$, viscosity and total solid: The interactive effect of temperature, charcoal thickness and Deola on viscosity keeping other at optimum point was shown in Figure 2a. Viscosity was decreasing with increasing temperature range from 73.59 to $82^{\circ} \mathrm{C}$. Viscosity decrease with the range of thickness from 0.83 to $1.25 \mathrm{~mm}$ and viscosity increase with thickness range from 1.25 to $1.67 \mathrm{~mm}$.

The interactive effect of temperature, charcoal thickness and Deola

\begin{tabular}{|l|c|c|c|c|c|}
\hline Source & DF & SS & MS & FCal & Ftab \\
\hline Model & 9 & 0.000431 & 0.000047 & $10.60^{* * *}$ & 4.94 \\
\hline Linear & 3 & 0.000194 & 0.000064 & $14.37^{* * *}$ & 4.94 \\
\hline Quadratic & 3 & 0.000111 & 0.000037 & $8.22^{* * *}$ & 4.94 \\
\hline Interactive & 3 & 0.000114 & 0.000038 & $8.44^{* * *}$ & \\
\hline Error & 10 & 0.000045 & 0.0000045 & & \\
\hline Total & $\mathbf{1 9}$ & $\mathbf{0 . 0 0 0 4 6 4}$ & & \\
\hline *** **,*Significant at 1,5 and $10 \%$ level of significance respectively
\end{tabular}

Table 7: ANOVA for Density.

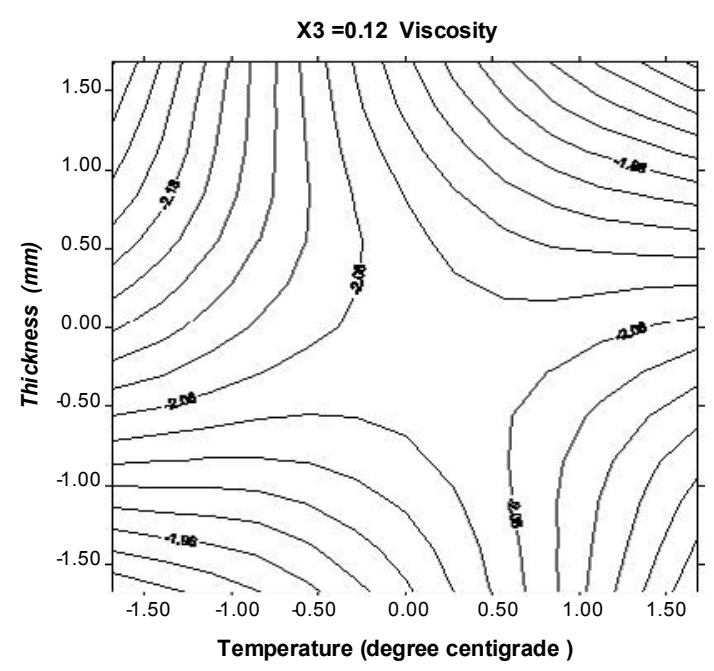

Figure 2a: Contour plot between temperature and thickness at optimum point. 
Citation: Umesh Kumar PK, Chand K (2015) Application of Response Surface Method as an Experimental Design to Optimize Clarification Process Parameters for Sugarcane Juice. J Food Process Technol 6: 422. doi:10.4172/2157-7110.1000422

Page 5 of 6

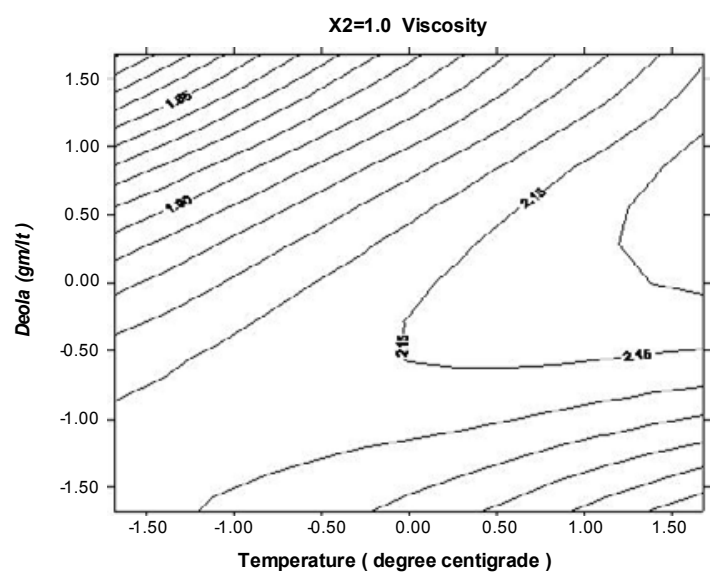

Figure 2b: Contour plot between temperature and deola at optimum point.

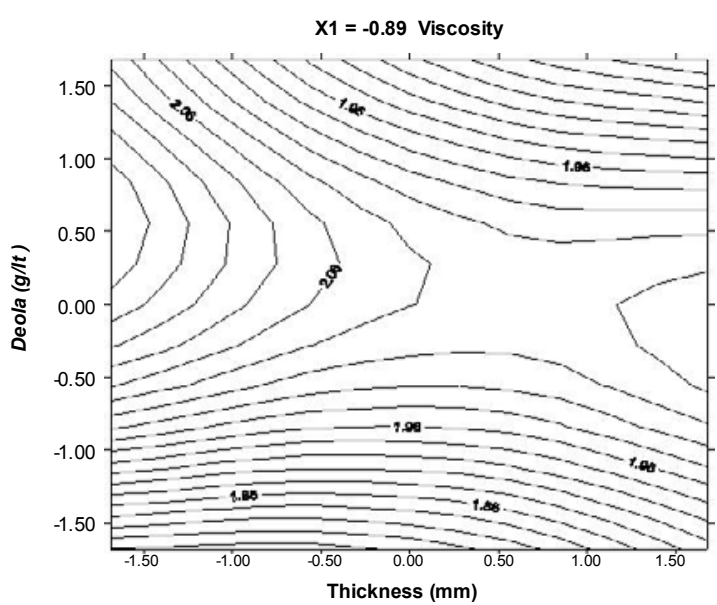

Figure 2c: Contour plot between deola and thickness at optimum point.

on viscosity keeping other at optimum point was shown in Figure $2 \mathrm{~b}$, Viscosity was decreasing with decreasing temperature range from 82 to $90.41^{\circ} \mathrm{C}$ and viscosity decrease with deola range from 0.4 to $0.74 \mathrm{~g} /$ lit.

The interactive effect of temperature, charcoal thickness and Deola on viscosity keeping other at optimum point was shown in Figure 2c. Viscosity was decreasing with decreasing thickness range from 1.25 to $1.67 \mathrm{~mm}$ and viscosity decrease with deola range from 0.4 to $0.74 \mathrm{~g} / \mathrm{lit}$.

The effect of temperature, charcoal thickness and Deola on ${ }^{\circ}$ Brix keeping other at optimum point was shown in Figure 3a. ${ }^{\circ}$ Brix was increasing with increasing temperature from 73.59 to $90.41^{\circ} \mathrm{C}$ and ${ }^{\circ}$ Brix decreasing with increasing with thickness from 1.25 to $1.67 \mathrm{~mm}$.

The effect of the parameters as temperature, charcoal thickness and Deola on ${ }^{\circ}$ Brix keeping other at optimum point was shown in Figure $3 \mathrm{~b}$ and $3 \mathrm{C} .{ }^{\circ} \mathrm{Brix}$ was increasing with increasing temperature range from 73.59 to $82^{\circ} \mathrm{C}$. But ${ }^{\circ} \mathrm{Brix}$ decrease with increases deola range from 0.4 to $0.74 \mathrm{~g} / \mathrm{lit}$.

The effect of the parameters as temperature, charcoal thickness and Deola on ${ }^{\circ}$ Brix keeping other at optimum point was shown in Figure $4 a-c$. ${ }^{\circ}$ Brix was increasing with increasing thickness range from 1.25 to $1.67 \mathrm{~mm}$. But ${ }^{\circ}$ Brix decrease with increases deola range from 0.4 to $0.74 \mathrm{~g} / \mathrm{lit}$.

\section{Conclusion}

This work has demonstrated the application of RSM in seeking optimal conditions for clarification process variables. In order to gain a better understanding of three factors for optimum clarification of

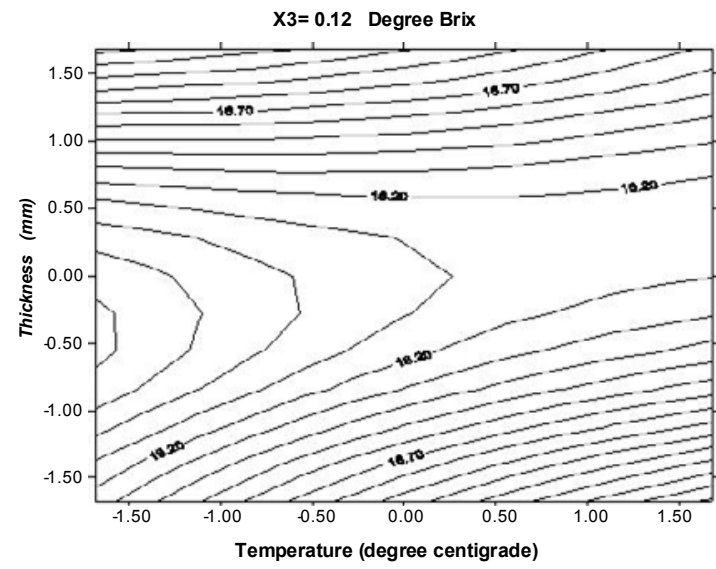

Figure 3a: Contour plot between temperature and temperature and thickness at optimum point.

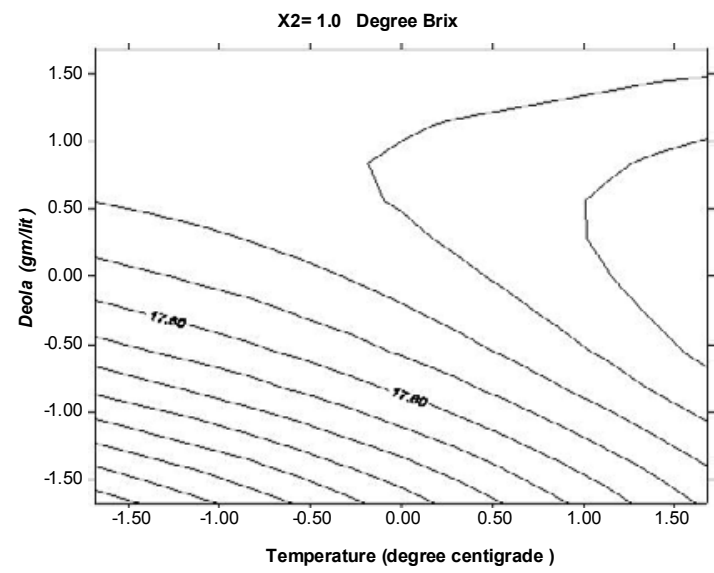

Figure 3b: Contour plot between deola at optimum point.

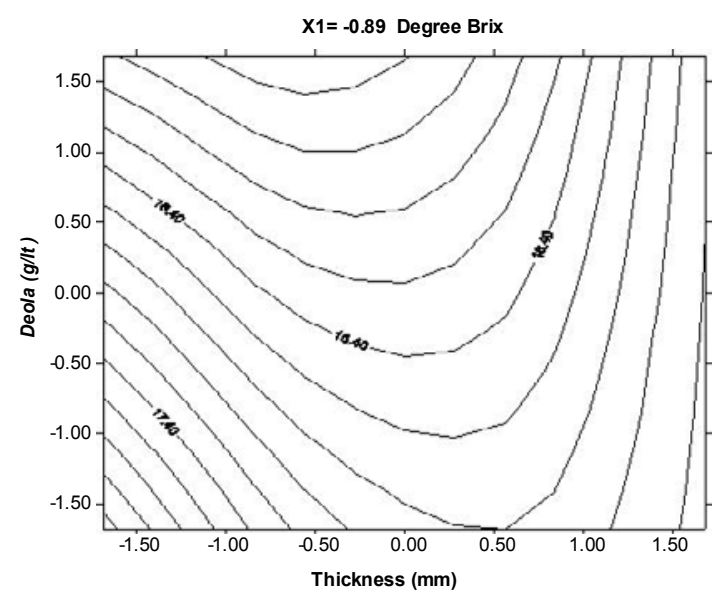

Figure 3c: Contour plot between deola and thickness at optimum point. 
Citation: Umesh Kumar PK, Chand K (2015) Application of Response Surface Method as an Experimental Design to Optimize Clarification Process Parameters for Sugarcane Juice. J Food Process Technol 6: 422. doi:10.4172/2157-7110.1000422

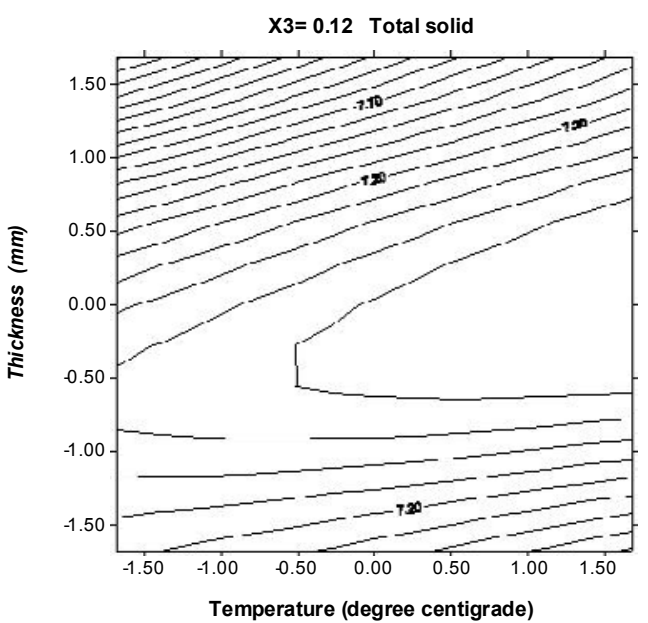

Figure 4a: Contour plot between temperature and Deola thickness at optimum point.

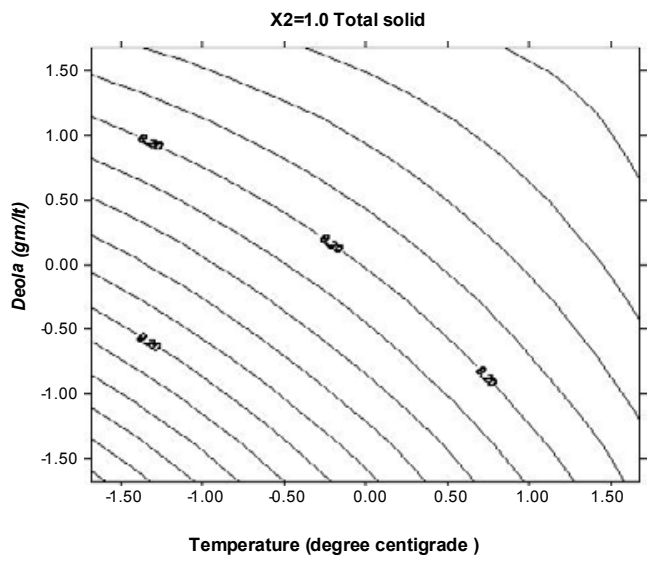

Figure 4b: Contour plot between temperature and at optimum point.

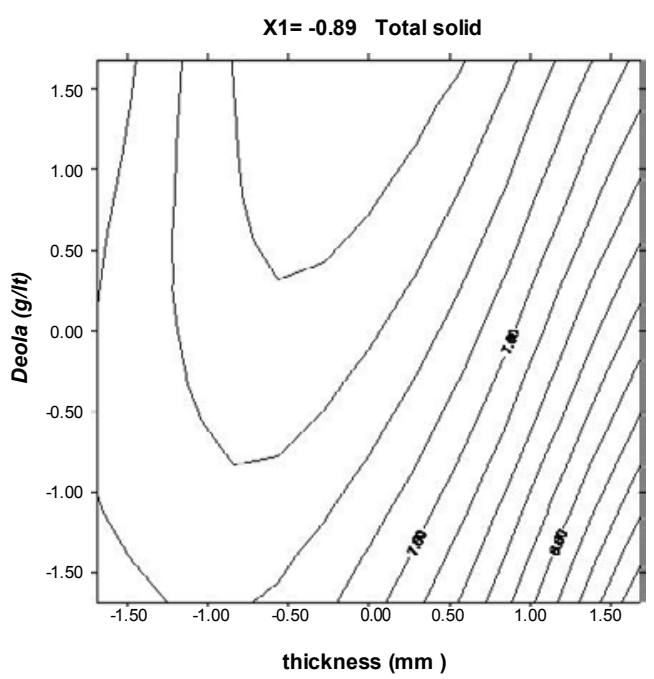

Figure 4c: Contour plot between deola and thickness at optimum point. juice, models were developed. From the statistical analysis, thickness of activated charcoal and deola have highest significant $(\mathrm{p}<0.01)$ effect on the response viscosity, ${ }^{\circ}$ Brix of sugarcane juice was highly effected by deola and is followed by thickness of activated charcoal and temperature.

\section{Acknowledgement}

This research was carried out in the department of Post Harvest Process and Food Engineering and funded by the Indian council of agriculture research project under All India coordinated research project on post harvest technology. We sincerely thanks to Director Research and Dean, College of Technology, G.B.P.U.A. and T., Pantnagar for providing necessary requirements for smooth conducting of the research work.

\section{References}

1. Anonymous (2011) Role of Bagacillo particles in Juice Clarification, Research Department, Sugar Udyog, India.

2. Pattanayak PK, Mishra MK (2004) Energetic and economics of traditional gur preparation: a case study in Ganjam district of Orissa, India. Biomass and Bioenergy 26: 79-88.

3. Nevkar GS, Thakor NJ, Patil AP, Patil DS (2005) Influence of packaging material on quality characteristics of jaggery at Kolhapur region. $40^{\text {th }}$ Annual convection and symposium of Indian Soc of Agril Engg TNAU, Coimbature.

4. Ghosh AK, Agarwal MP (1983) Gur grading based on physical and chemical constituents. Maharashtra Sugar 8: 39-43.

5. Ojha SK, Singh JP, Ahmed N (1973) Factors affecting Juice quality of Sugarcane-A Review, Indian Sugar 22: 861-866.

6. Garg A (1978) Phospolipids in sugarcane juice and their fate during the process of clarification. Indian Sugar 28: 423-431.

7. Rao KKP (1973) Recent trends in jaggery research. Diamond Jubilee Souvenir, Sugarcane Research Station, Anakapalle.

8. Montgomery DC (2001) Design and analysis of experiments. John Wiley \& Sons, New York.

9. Box GEP, Hunter JS (1957) Multi-factor experimental designs for exploring response surfaces. Ann Math Statist 28: 195-241. 